eISSN 2444-7986

DOI: http://dx.doi.org/10.14201/orl201672.13998

\title{
Editorial
}

\section{ORCID: SISTEMA DE IDENTIFICACIÓN UNÍVOCA DE AUTORES}

\author{
ORCID: Unique Author Identifier System
}

\author{
Helena MARTÍN-RODERO \\ Universidad de Salamanca. Facultad de Medicina. Biblioteca. Salamanca. España. \\ http://orcid.org/0000-0002-6698-9240. \\ Revista ORL. Consejo Editorial. \\ Correspondencia: helena@usal.es
}

Fecha de Publicación: 3 de marzo de 2016

Conflicto de intereses: Los autores declaran no tener conflictos de intereses Imágenes: Los autores declaran haber obtenido las imágenes con el permiso de los pacientes Política de derechos y autoarchivo: se permite el autoarchivo de la versión post-print (SHERPA/RoMEO) Licencia CC BY-NC-ND. Licencia Creative Commons Atribución-NoComercial-SinDerivar 4.0 Internacional (C) Universidad de Salamanca. Su comercialización está sujeta al permiso del editor

En un artículo de la Australian National Data Service Share NewsLetter, Susannah Sabine [1] ponía de manifiesto que, de los más de 6 millones de autores citados en las principales revistas y bases de datos, más de dos tercios compartían apellido e inicial del nombre con otro autor y esta ambigüedad, en una misma base de datos, puede afectar a un promedio de 8 personas. Esto sucede de manera generalizada y global. En relación a los autores españoles el asunto se complica. Un estudio publicado en el Journal of Medical Library Association encontró que más de un $69 \%$ de los autores españoles aparecían indexados en las bases de datos por más de un nombre [2].

¿Qué sucede, cuando los autores no sólo comparten nombre sino también área de especialización o pertenecen a la misma institución; o cuando los nombres no están correctamente escritos o cuando no han sido correctamente indexados en las bases de datos? Es fácil de imaginar, que muchas de las contribuciones científicas correrán el riesgo de no ser correctamente atribuidas a sus autores, con las consiguientes dificultades para la evaluación de los mismos y la cuantificación de sus obras.

El problema de la identificación correcta de los autores es antiguo y afecta, no solo a los autores, sino a otros investigadores en la búsqueda de referencias que sustenten sus trabajos de investigación, a la visibilidad de sus instituciones o a la financiación de sus proyectos.

Para solucionar este problema han ido surgiendo distintos sistemas de identificación de autor como IraLIS, ResearcherID (Thomson Reuters), Author Identifier (Scopus), entre otros, pero ninguno de ellos con intención integradora y globalizadora [3].

Por este motivo surge a finales de 2009 el proyecto ORCID (www.orcid.org), respaldado por 23 organizaciones entre las que se encuentran Thomson Reuters, Nature Publishing Group, Elsevier, Proquest, Springer, CrossRef, The British Library y el Wellcome Trust [5]. ORCID es una iniciativa abierta, sin ánimo de lucro, interdisciplinaria, de aplicación global e independiente e impulsada por 
la comunidad de participantes: investigadores, editores, instituciones académicas y de investigación, agencias de financiación, agencias nacionales y compañías del sector y financiada por las organizaciones miembro [4].

¿Qué es ORCID ID? El Open Research and Colaborate Identifier (ORCID) es un estándar para la identificación única y persistente de los autores del ámbito académico y de la investigación. Se trata de una cadena alfanumérica que identifica de forma exclusiva a un científico de la misma manera que el DOI (Digital Object Identifier) identifica de forma unívoca un documento, libro u otra publicación académica.

El sistema permite distinguir, en el universo de la comunicación científico-académica, entre la pléyade de "Martín-García J», que no se verán afectados ni por los cambios de nombre, ni por las diferencias culturales en el orden del nombre, sus abreviaturas e iniciales o el uso de diferentes alfabetos.

El identificador ORCID se desarrolló a partir del software utilizado por Thomson Reuters para su sistema de identificación ResearcherID. Se basa en la norma ISO 2279:21012 (Information and Documentation International Standard Name Identifier). Está compuesto de 16 dígitos y se expresa como una URI (Uniform Resource Identifier o Identificador de Recursos Uniforme -http://orcid.org/00000002-6698-9240-).

¿Por qué es importante para los investigadores? ORCID ID facilita la desambiguación de nombres permitiendo la identificación no sólo de los autores sino también de sus trabajos y actividades profesionales. Posibilita la interacción correcta con otros identificadores como ResearcherID (Thomson Reuters) o el Author Identifier (Scopus).

Permite la integración en los sistemas de gestión de la producción científica (CRIS y repositorios), en los flujos del trabajo editorial y en los flujos de trabajo de la investigación. Asimismo ORCID favorece la asociación a las solicitudes de financiación y al estándar CVN (curriculum vitae normalizado) de la FECYT (www.fecyt.es)
La obtención del identificador ORCID es gratuito para investigadores y académicos que además poseerán el control sobre la información de sus perfiles.

¿Por qué es importante para las Instituciones? ORCID ID favorece la gestión interoperable de la identificación del personal docente e investigador, ofreciendo una mayor facilidad en la recuperación de sus publicaciones, una gestión más eficaz de la actividad investigadora en los procesos de evaluación y una mayor presencia y visibilidad internacional de investigadores y de la propia institución y finalmente permite la integración en sistemas administrativos (RRHH, nóminas) y de gestión de la información (CRIS, repositorios) [6].

¿Por qué es importante para los editores? ORCID ID mejorará la comunicación con los autores, incluido el proceso de peer review. La implicación de las editoriales con el proyecto es una realidad. El reciente lanzamiento de la funcionalidad de actualización automática de CrossRef significa que los investigadores pueden optar por tener su registro ORCID actualizado automáticamente cuando se publican sus trabajos, y esto, a su vez, significa que las universidades y otros sistemas podrán recibir actualizaciones directamente, reduciendo la carga de informes sobre los investigadores y simplificando los procesos.

ORCID ID se vislumbra ya como la solución definitiva al problema de la identificación correcta de los autores y anticipa un futuro prometedor para todos los actores que participan en los procesos de comunicación de la ciencia: autores e instituciones, agencias de financiación, editoriales y agencias de evaluación.

\section{REFERENCIAS}

1. Sabine $S$. You know who you are, but do others? Share Neswletter Aust Natl Data Serv. 2014;18:5.

2. Ruiz-Pérez R, Delgado López-Cózar E, Jiménez-Contreras E. Spanish personal name variations in national and international biomedical databases: implications for information retrieval and bibliometric studies. J Med Libr Assoc JMLA. 2002;90(4):411-30. 
3. García-Gómez C. ORCID: un sistema global para la identificación de investigadores. El Prof Inf [Internet]. 2012 [citado 2016 feb 19];21(2):210-2. Disponible

en:

http://recyt.fecyt.es/index.php/EPI/articl e/view/epi.2012.mar.14.

4. ORCID. What is ORCID? [Internet]. [citado 2016 feb 28]; Disponible en: http://orcid.org/.
5. Credit where credit is due [Editorial]. Nature. 2009;462:825.

6. Guías de la BUS. ORCID [Internet]. [citado 2016 feb 28]; Disponible en: http://guiasbus.us.es/orcid. 